\title{
Anatomia da raiz de Cyperus giganteus Vahl (Cyperaceae) em desenvolvimento
}

\author{
ANA CLAUDIA RODRIGUES ${ }^{1,2}$ e MARIA EMÍLIA M. ESTELITA ${ }^{1}$
}

(recebido: 5 de dezembro de 2001; aceito: 1 de julho de 2004)

\begin{abstract}
Developmental root anatomy of Cyperus giganteus Vahl (Cyperaceae). Cyperus giganteus or "piri”, constitutes a vegetable community denominated "Pirizal", in the Pantanal. It is considered an amphibious or mesophyte species, because it grows in ponds or dry soils. In the tip root there is the calyptrogen, from which the root cap originates; the promeristem, the protoderm, the procambium and the fundamental meristem are also evident in this part. During the differentiation of the protoderm and of the fundamental meristem from promeristem, the initial cell of both tissues can be observed. The external cortex is constituted by the hypodermis and the inner cortex is formed from the precursory layer of the endodermis. The endodermis presents Casparian strip, suberin lamella, thickened walls and phenolic compounds. In successive phases the inner cortex presents schizo-lysigenous aerenchyma. Precocious metaxylem elements are observed in the vascular cylinder followed by the protoxylem elements differentiation. During the development of the rhizome, the roots arise from the pericycle, that constitutes the innermost layer of the primary thickening meristem (PTM). The disposition of the aerenchyma, the multiple hypodermis and idioblasts with phenolic componds are the most representative characters in the root organization for the family Cyperaceae.
\end{abstract}

Key words - Cyperaceae, Cyperus giganteus, root anatomy

RESUMO - (Anatomia da raiz de Cyperus giganteus Vahl (Cyperaceae) em desenvolvimento). No Pantanal Cyperus giganteus ou "piri", constitui uma comunidade vegetal "Pirizal". É considerada espécie anfíbia ou mesófita, pois ocorre tanto em lagoas e/ou em solos secos. No ápice radicular são evidentes o caliptrogênio, que origina a coifa; o promeristema; a protoderme; o procâmbio e o meristema fundamental. A partir do promeristema identifica-se a célula que dá origem à protoderme e ao meristema fundamental. O córtex externo é constituído pela hipoderme; o córtex interno é formado a partir da camada precursora da endoderme, com formação do aerênquima esquizolisígeno. A endoderme apresenta estrias de Caspary, lamela de suberina, paredes espessadas e impregnada com compostos fenólicos. Observa-se no cilindro vascular a diferenciação precoce dos elementos do metaxilema, seguida pela diferenciação dos elementos do floema. No rizoma, as raízes se originam do periciclo, o qual constitui a camada mais interna do meristema de espessamento primário (MEP). A raiz tem como caracteres representativos da família Cyperaceae a disposição do aerênquima, a hipoderme plurisseriada e idioblastos com compostos fenólicos.

Palavras-chave - anatomia, Cyperaceae, Cyperus giganteus, raiz

\section{Introdução}

Entre as espécies do Pantanal sul-mato-grossense Cyperus giganteus Vahl ocorre em pequenas lagoas formando comunidades vegetais denominadas "Pirizal" (Allem \& Valls 1987); também tolera a dessecação do solo, sendo considerada, portanto, anfíbia (Scultorpe 1967). O sistema subterrâneo é constituído por um rizoma plagiotrópico com entrenós contraídos, cujas gemas laterais dão origem a novas unidades simpodiais; ainda, estão presentes raízes adventícias relativamente delgadas e tenras (Rodrigues \& Estelita 2002).

\footnotetext{
1. Universidade de São Paulo, Instituto de Biociências, Departamento de Botânica, Caixa Postal 11461, 05422-970 São Paulo, SP, Brasil.

2. Autor para correspondência: anclaro@uol.com.br
}

Etapas de diferenciação de raízes de monocotiledôneas são descritas em trabalhos como o de Riopel \& Steeves (1964), Tomlinson (1969) e Clark \& Harris (1981) que analisaram Musa acuminata, Thalassia testudinum e Oriza sativa, respectivamente. Wilder (1986a, b) estudou as raízes de primeira ordem de espécies de Cyclantaceae e Seubert (1997) analisou a anatomia das raízes palmeiras. Com espécies brasileiras foram realizados trabalhos como o de Scatena \& Menezes (1996) que descreveram a anatomia de espécies de Syngonanthus, Alquini \& Morretes (1996) que analisaram as raízes de Musa rosaceae, Vianna et al. (2001) que descreveram as raízes escoras de Philodendron bipinnatifidum (Araceae) e Pita \& Menezes (2002) sobre Bromeliaceae. Entretanto, em todos esses trabalhos não foram abordados aspectos de diferenciação.

Dentre os estudos sobre raízes em espécies de Cyperaceae, além do clássico trabalho de Metcalfe 
(1971), que cita aspectos gerais dos vários órgãos, destacam-se o trabalho de Kadej (1963) que observou o padrão de disposição das células do meristema apical de Cyperus gracilis L. var. alternifolius comparando-o com o ápice radicular das pteridófitas, e o trabalho de Davies et al. (1973) que estudaram as raízes laterais intumescidas de várias espécies de Cyperaceae. Outros trabalhos como de Kukkonen (1967) e Estelita (1993) trazem informações sobre o sistema radicular de Uncinia e Remirea, respectivamente. Certos caracteres anatômicos da raiz de espécies de Cyperaceae são citados como subsídios à sistemática por Govindarajalu (1974) e Sharma \& Mehra (1972).

As raízes adventícias das monocotiledôneas originam-se na sua maioria de um meristema periférico ao cilindro vascular denominado "meristema de espessamento primário" ou MEP (Rudall 1991, DeMason 1979, 1983). Gifford \& Bayer (1995) analisando $C$. esculentus consideram as raízes também originadas do MEP, porém o denominaram camada endodermóide; por outro lado, Wills et al. (1980) observaram que em $C$. esculentus as raízes se formam a partir da endoderme.

O presente trabalho aborda a origem e as etapas do desenvolvimento das raízes de $C$. giganteus para contribuir com informações sobre a organização do sistema radicular das Cyperaceae.

\section{Material e métodos}

Espécimes de Cyperus giganteus foram coletados no Pantanal de Miranda e do Abobral, sub-regiões do sul do Pantanal sul-mato-grossense. Parte do material encontra-se registrado no herbário como SPF 138.170 e 138.174.

Fragmentos da raiz foram fixados com FAA 50 (Johansen 1940) por 72 horas e estocados em etanol $70 \%$. Para o estudo do desenvolvimento foram retiradas amostras da região apical e confeccionadas lâminas permanentes, utilizando-se o processo de desidratação em série butanólica terciária (Johansen 1940) a partir da concentração alcoólica do fixador. O material foi incluído em parafina e seccionado em micrótomo Leica - Reichert-Jung 2040, com navalha de aço, com espessura entre 8 a $15 \mu \mathrm{m}$. Depois de distendido em lâminas o material foi corado pela safranina e azul de astra (Bukatsch 1972) e montado em bálsamo-do-canadá.

Os testes microquímicos foram realizados utilizando-se solução de Lugol para o amido, Sudam IV para substâncias lipofílicas (Sass 1951) e cloreto férrico para substâncias fenólicas (Johansen 1940).

A documentação foi realizada em microscópio Olympus - Vanox e microscópio Jenamed equipado com luz polarizada.

\section{Resultados}

As raízes de $C$. giganteus surgem principalmente na região do rizoma de maior contato com o solo; algumas delas ramificam-se até primeira ordem.

Em secções longitudinais do ápice radicular são evidentes a coifa originada do caliptrogênio, o promeristema, a protoderme, o procâmbio e o meristema fundamental (figuras 1,2). O caliptrogênio é constituído por camadas celulares estratificadas, com paredes finas, núcleos proeminentes e citoplasma denso (figura 2). A coifa é formada por divisões periclinais do mesmo e contém várias camadas compactadas de células, com considerável quantidade de idioblastos com substâncias fenólicas (figura 1). Parte do promeristema origina a protoderme e o meristema fundamental, sendo ambos originados de uma célula inicial comum (figura 2, setas). O procâmbio é evidenciado muito próximo à região do promeristema; nele os elementos do metaxilema começam a se diferenciar precocemente (figura 1).

Em secções transversais do ápice radicular observam-se inicialmente a região do promeristema e camadas da coifa com considerável quantidade de compostos fenólicos (figura 3). À aproximadamente $65 \mu \mathrm{m}$ do ápice radicular, observa-se atividade do promeristema resultando na protoderme, meristema fundamental e procâmbio (figura 4); à cerca de $100 \mu \mathrm{m}$ o córtex e o cilindro central estão definidos e neste último inicia-se a diferenciação do metaxilema (figura 5). A camada mais interna do córtex, ou camada precursora da endoderme, divide-se inúmeras vezes no sentido periclinal formando extratos celulares radiais do córtex interno (figura 5). Em níveis posteriores, onde ainda estão presentes camadas da coifa observa-se a epiderme em diferenciação e o córtex externo apresentando camadas celulares não ordenadas (figura 6).

A aproximadamente a $220 \mu \mathrm{m}$ (figura 7) inicia-se, na região procambial, a diferenciação do protofloema; observa-se, ainda, metaxilema e divisões da camada precursora da endoderme. Em níveis subseqüentes observa-se marcante diferença entre a organização celular do córtex externo e interno (figura 8). O córtex externo contém aproximadamente seis camadas de células de contorno hexagonal, com poucos meatos e constitui uma hipoderme. O córtex interno é formado por extratos celulares radiais, cujas células de formato octogonal delimitam consideráveis espaços celulares (figura 8). As células corticais apresentam-se vacuoladas com núcleo na posição central e pontes citoplasmáticas perceptíveis, indicando que se encontram em estágios semelhantes de diferenciação (figuras 8, 9). 

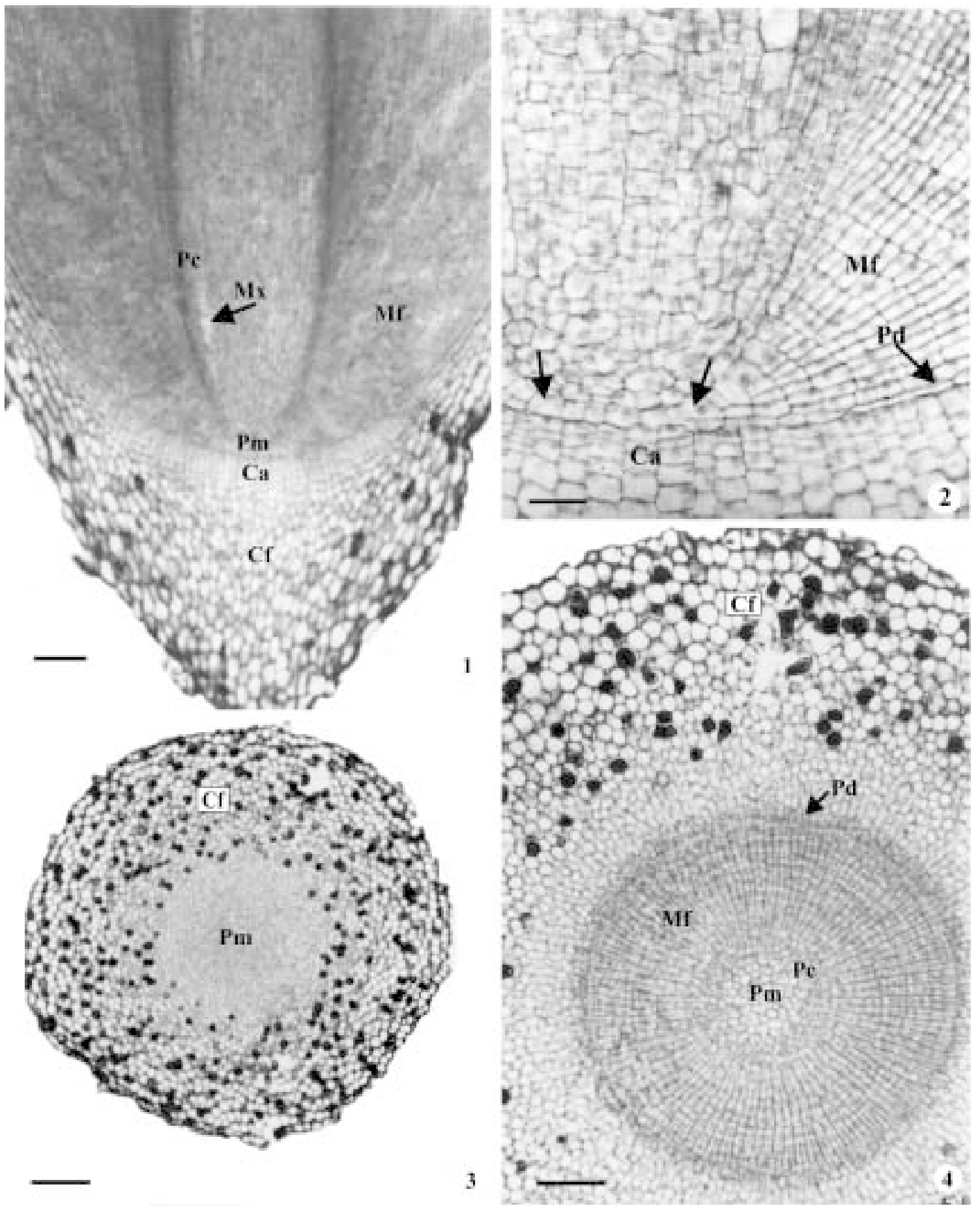

Figuras 1-4. Ápice radicular. 1-2. Secções longitudinais medianas do ápice radicular. 1. Organização do ápice radicular. 2. Células iniciais (setas) comuns ao meristema fundamental e a protoderme. 3-4. Secções transversais do ápice radicular. 3. Promeristema e coifa com idioblastos com substâncias fenólicas. 4. Promeristema formando o procâmbio, o meristema fundamental e a protoderme; observa-se ainda células da coifa. $(\mathrm{Cf}=$ coifa; $\mathrm{Ca}=$ caliptrogênio; $\mathrm{Pm}=$ promeristema; $\mathrm{Pd}=$ protoderme; $\mathrm{Mf}=$ meristema fundamental; $\mathrm{Pc}=$ procâmbio; $\mathrm{Mx}=$ metaxilema). Barras $=120 \mu \mathrm{m}(1,3), 30 \mu \mathrm{m}(2), 60 \mu \mathrm{m}(4)$.

Figures 1-4. The root apex. 1-2. Median longitudinal sections of the root apex. 1. Root apex organization. 2. Common initial cells (arrow) to the ground meristem and protoderm. 3-4. Cross-sections of root apex. 3. Promeristem and root cap with phenolic compounds idioblasts. 4. Promeristem differentiating the procambium; ground meristem and protoderm; the section showing too root cap cells. $(\mathrm{Cf}=$ root cap; $\mathrm{Ca}=$ calyptrogen; $\mathrm{Pm}=$ promeristem; $\mathrm{Pd}=$ protoderm; $\mathrm{Mf}=$ ground meristem; $\mathrm{Pc}=$ procambium; $\mathrm{Mx}=$ metaxylem). Bars $=120 \mu \mathrm{m}(1,3), 30 \mu \mathrm{m}(2), 60 \mu \mathrm{m}(4)$. 

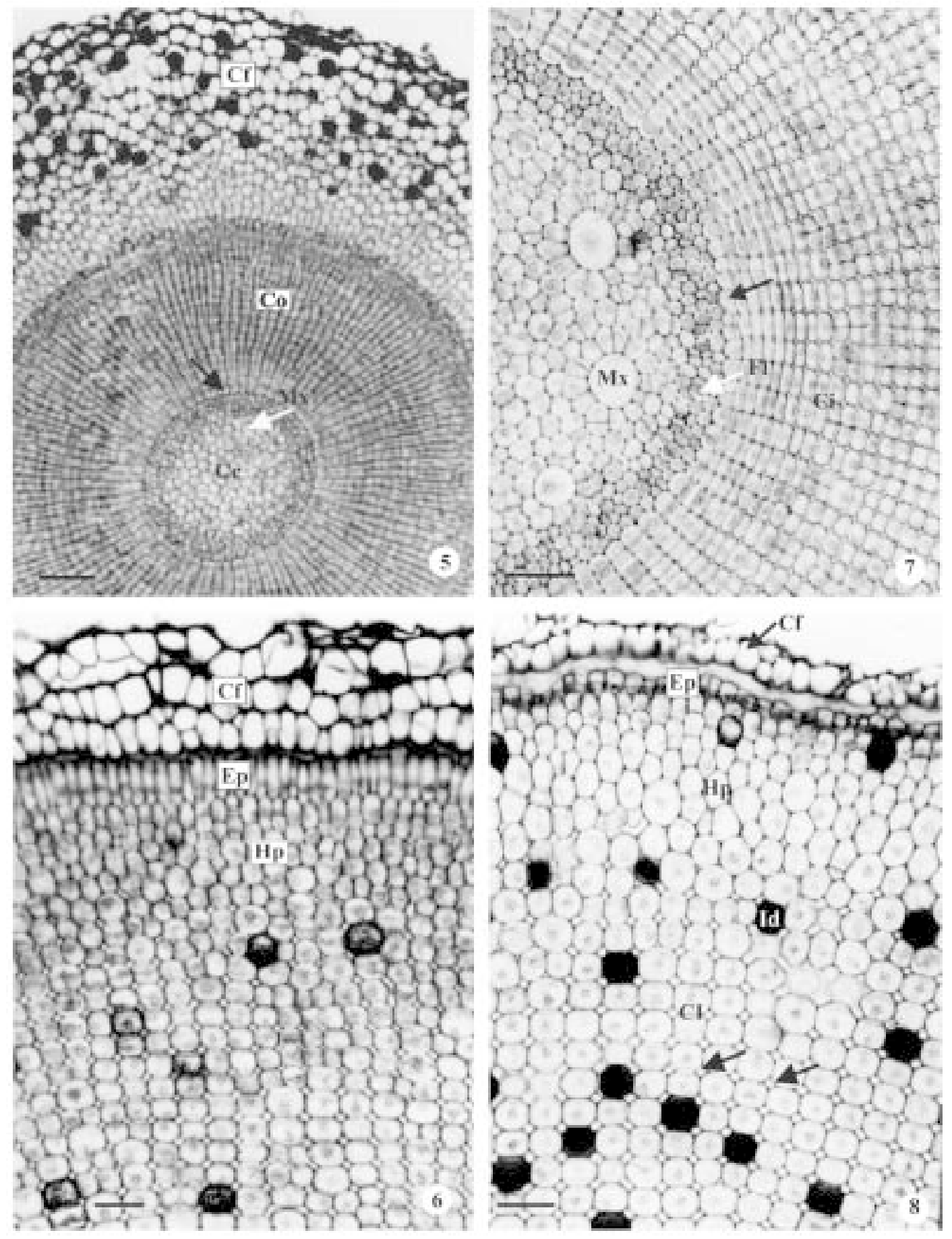

Figuras 5-8. Secções transversais da raiz. 5. Formação do córtex por divisões da camada precursora da endoderme (seta) e início da diferenciação do metaxilema. 6. Diferenciação da epiderme e da hipoderme. Observa-se ainda, algumas camadas da coifa. 7. Divisões da camada precursora da endoderme (seta) e diferenciação do metaxilema e do floema. 8. Córtex externo (hipoderme) e córtex interno; este último mostrando idioblastos e espaços intercelulares conspícuos (setas). $(\mathrm{Cc}=$ cilindro central; $\mathrm{Co}=$ córtex; $\mathrm{Cf}=$ coifa; $\mathrm{Mx}=$ metaxilema; $\mathrm{Fl}=$ floema; $\mathrm{Ci}=$ córtex interno; $\mathrm{Ep}=$ epiderme; $\mathrm{Hp}=$ hipoderme; $\mathrm{Id}=$ idioblastos $)$. Barras $=60 \mu \mathrm{m}$ (5), $30 \mu \mathrm{m}(6-8)$.

Figures 5-8. Root cross-sections. 5. Cortex from endodermis precursor layer divisions (arrow) and the beginning of metaxylem differentiation. 6. Yong epidermis and hypodermis; some layers of root cap are observed. 7. Divisions of the endodermis precursor layer (arrow) and metaxylem and phloem differentiation. 8. Outer cortex (hypodermis) e inner cortex; the last one showing idioblasts and intercellular spaces (arrow). $(\mathrm{Cc}=$ vascular cylinder; $\mathrm{Co}=\mathrm{cortex} ; \mathrm{Cf}=$ root cap; $\mathrm{Mx}=$ metaxylem; $\mathrm{Fl}=$ phloem $; \mathrm{Ci}=$ inner cortex $; \mathrm{Ep}=$ epidermis; $\mathrm{Hp}=$ hypodermis; $\mathrm{Id}=$ idioblasts). $\mathrm{Bars}=60 \mu \mathrm{m}(5), 30 \mu \mathrm{m}(6-8)$. 
Idioblastos com substâncias fenólicas são evidenciados, principalmente no córtex interno (figura 8). O protofloema é conspícuo e o protoxilema, a endoderme e o periciclo encontram-se em diferenciação (figura 9).

Em níveis subseqüentes, as células da endoderme encontram-se altamente vacuoladas (figura 10) e com estrias de Caspary perceptíveis (figura 13); nesta região, observa-se a formação de raízes laterais. Em seguida, as células do córtex interno tornam-se gradativamente braciformes aumentando os espaços intercelulares (figura 10). Entre elas estão presentes idioblastos com substâncias fenólicas que se alongam no sentido axial. As camadas mais internas do córtex adquirem paredes secundárias que se lignificam (figura 10). Nessa região observa-se a deposição da lamela de suberina, na endoderme, e a lignificação do parênquima medular (figuras 14, 15). Em regiões subsequientes, as células da hipoderme se impregnam de substâncias lipofílicas e fileiras de células braciformes, do córtex interno, colapsam em arranjo radial finalizando a diferenciação do aerênquima (figuras 15, 16). As células da endoderme adquirem espessamento e sofrem lignificação e impregnação por substâncias fenólicas (figura 16). A raiz madura apresenta cerca de 30 polos de protoxilema; estando também presentes alguns idioblastos na região medular.

A formação das raízes laterais ocorre com participação da endoderme (figura 11) e por ruptura dos tecidos corticais, cujos primórdios radiculares apresentam a região do promeristema truncada (figura 12).

\section{Discussão}

De acordo com Clowes (1981) a organização apical das raízes pode ser do tipo aberto ou fechado. No primeiro, as fileiras de células derivadas do meristema apical parecem ser contínuas com as fileiras de células da coifa. No tipo fechado, como em Zea mays, as células derivadas do meristema apical convergem para um ponto comum (Torrey \& Feldman 1977). No ápice radicular do tipo fechado ocorrem três grupos de células iniciais: um para o cilindro central, um para o córtex e outro para a coifa podendo a epiderme ter origem das iniciais do córtex ou da coifa (Esau 1967). A organização apical da raiz de $C$. giganteus é do tipo fechado e pode-se perceber que ocorrem iniciais do cilindro central, do córtex e da coifa, independentemente. Observa-se também, que a epiderme tem a mesma origem das células corticais, como ocorre comumente nas monocotiledôneas (Rost 1994, Clowes 1994, 2000).
O ápice radicular de Cyperus giganteus assemelha-se ao de Triticum analisado por Clowes (1954, 1994); situação análoga foi registrada anteriormente por Kadej (1963) em C. gracilis. Entretanto, para Kadej (1963) os grupos de células iniciais em $C$. gracilis formam complexos de segmentos que se assemelham às raízes das pteridófitas sugerindo que em ambos os casos o modo de crescimento do meristema seja o mesmo. Discorda-se do referido autor, em virtude de nas pteridófitas ocorrer apenas uma única célula inicial e não grupo de iniciais como aqui respaldado.

A secreção de mucilagem no ápice radicular de em Cyperus giganteus é pouco perceptível, entretanto, ocorrem muitos idioblastos com substâncias fenólicas que, provavelmente, protegem o órgão contra microorganismos e herbívoros, pois principalmente os taninos reduzem a digestabilidade dos tecidos das plantas o que minimiza a atuação de herbívoros e patôgenos (Howe \& Westley 1988). Os taninos também podem se combinar com polissacarídeos da parede celular aumentando a dureza e dificultando a sua digestão e decomposição (Zucker 1983).

A diferenciação acrópeta do xilema em raízes de Cyperus giganteus também foi descrita por autores como Esau (1943), Heimsch (1951), Riopel \& Steeves (1964) entre outros, para outras espécies. Os primeiros elementos vasculares que se diferenciam são os do metaxilema mais os primeiros elementos que se tornam funcionais são os do protoxilema (Esau 1940). De acordo com Riopel \& Steeves (1964) o reconhecimento dos estágios iniciais de diferenciação do floema é difícil devido ao seu padrão irregular de vacuolação e diâmetro celular pequeno. Após a vacuolação as células do floema amadurecem rapidamente e o protofloema alcança a maturação muito mais perto do ápice do que os elementos do xilema.

O córtex interno da raiz de Cyperus giganteus é formado pela camada precursora da endoderme, ou seja, a camada que por divisões periclinais, origina o córtex (ou parte dele) e que dá origem também à endoderme segundo Van Fleet (1961). Esta camada foi citada por Williams (1947), Riopel \& Steeves (1964) em Musa acuminata, Seago \& Marsh (1989) em Typha glauca, Seago et al. (1999) em Hydrocharis morus-ranae e Seago et al. (2000) em Pontederia cordata. Para Williams (1947) esta camada atua como um câmbio, que através de divisões periclinais origina todos os tecidos desde a endoderme até a hipoderme em arranjo radial. A hipoderme em $C$. giganteus origina-se independentemente como também observado por Seago \& Marsh (1989) em Typha glauca. Enfatiza-se que, 


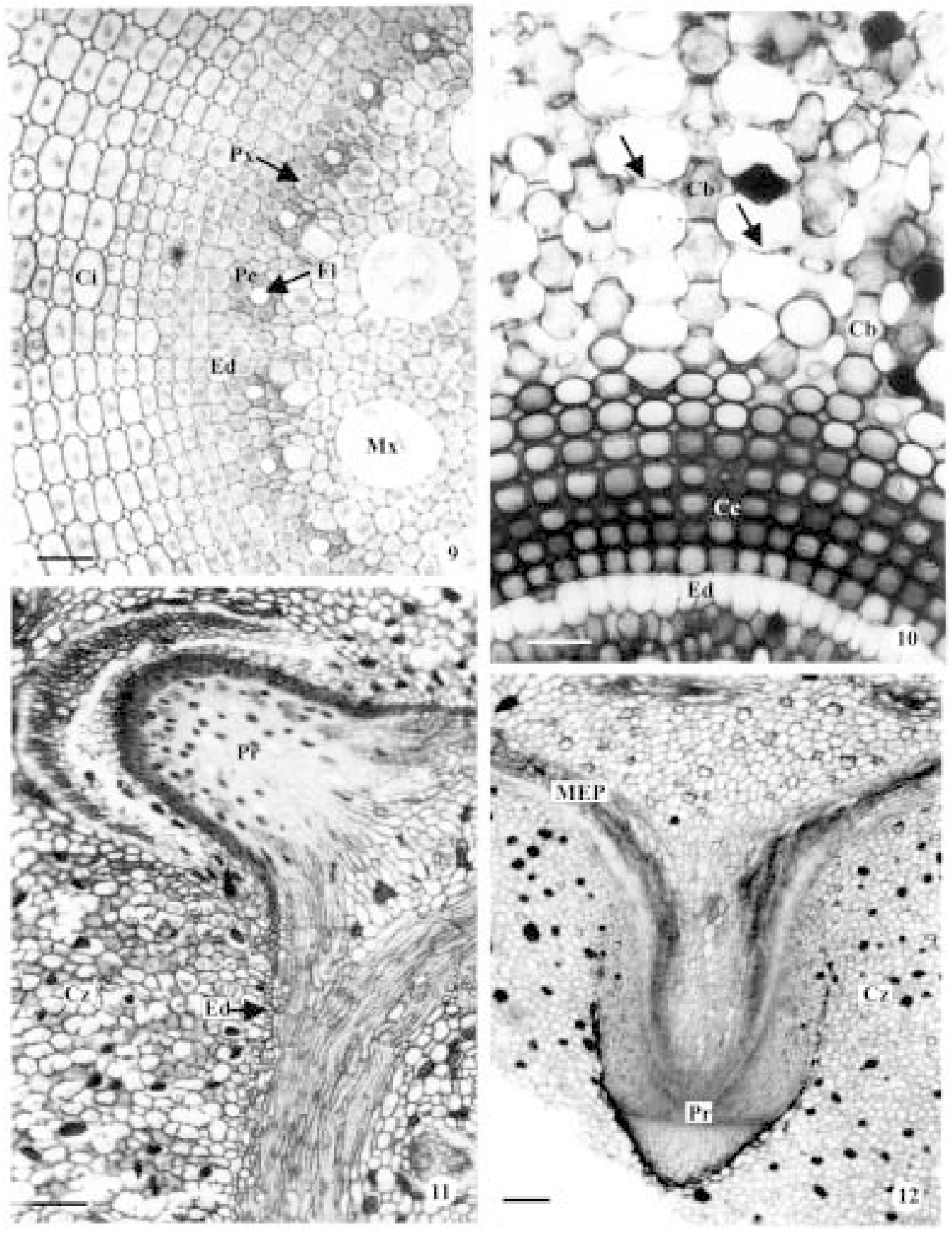

Figuras 9-12. Raiz. 9-10. Secções transversais. 9. Raiz jovem mostrando a diferenciação do córtex interno, da endoderme, periciclo, floema, protoxilema e metaxilema. 10. Endoderme, células corticais internas espessadas e o aerênquima com células braciformes e colapsadas (setas). 11-12. Formação de primórdios radiculares. 11. Raiz lateral formada a partir do periciclo. 12. Primórdio radicular truncado. Observa-se também o meristema de espessamento primário. $(\mathrm{Ed}=$ endoderme; $\mathrm{Pe}=$ periciclo; $\mathrm{Fl}=$ floema $; \mathrm{Px}=$ protoxilema $; \mathrm{Mx}=$ metaxilema $; \mathrm{Ci}=$ córtex interno $\mathrm{Cb}=$ células corticais braciformes $; \mathrm{Cc}=$ células corticais internas espessadas; $\mathrm{Pr}=$ primórdio radicular; $\mathrm{Cz}=$ córtex do rizoma; $\mathrm{MEP}=$ meristema de espessamento primário). Barras $=30 \mu \mathrm{m}$ $(9-11), 60 \mu \mathrm{m}(12)$.

Figures 9-12. Root. 9-10. Cross-sections. 9. Young root showing the differentiation of inner cortex, endodermis, pericycle, phloem, protoxylem and metaxylem. 10. Endodermis, thickened inner cortical cells and armed and collaped cells of the aerenchyma (arrow). 11-12. The beginning of root primordium. 11. Lateral root from pericycle. 12. Truncate root primordium. The section showing the primary tickening meristem too. $(\mathrm{Ed}=$ endodermis; $\mathrm{Pe}=$ pericycle $; \mathrm{Fl}=$ phloem; $\mathrm{Px}=$ protoxylem; $\mathrm{Mx}=$ metaxylem; $\mathrm{Ci}=$ inner cortex $\mathrm{Cb}=$ armed cortical cells; $\mathrm{Cc}=$ thickening inner cortical cells; $\mathrm{Pr}=$ root primordium; $\mathrm{Cz}=$ cortex of the rhizome; $\mathrm{MEP}=$ primary thickening meristem). Bars $=30 \mu \mathrm{m}(9-11), 60 \mu \mathrm{m}(12)$. 
em Cyperaceae a hipoderme pode ocorrer até as folhas (Metcalfe 1971), como observado em C. corymbosus e Remirea maritima (Estelita 1993).

Espaços intercelulares esquisógenos e lisígenos podem se formar no córtex radicular (Riopel \& Steeves 1964) e estão presentes em espécies de Gramineae, Cyperaceae e palmeiras, entre outras monocotiledôneas e são comuns em plantas aquáticas (Scultorpe 1967). Cyperus giganteus apresenta lacunas corticais esquisolisígenas. De acordo com Mani (1962) espaços lisígenos são comuns em raízes de várias espécies de Cyperus e se formam pela quebra das células corticais sem a formação de célula estrelada. Em $C$. giganteus ocorre inicialmente a diferenciação de células em forma de
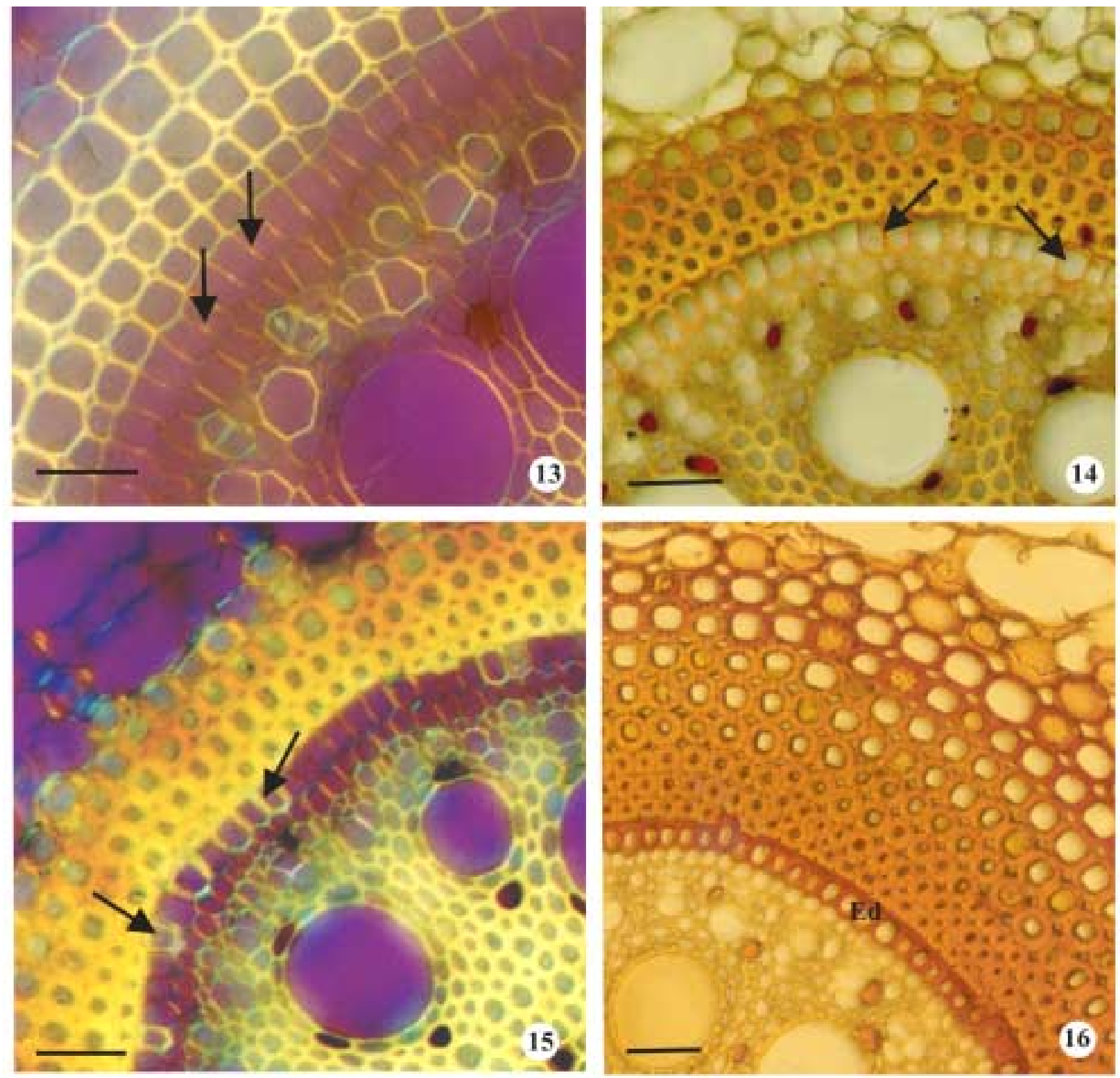

Figuras 13-16. Secções transversais da raiz. 13. Luz polarizada destacando estrias de Caspary (setas). 14-15. Luz polarizada mostrando a lamela de suberina na endoderme (setas). 16. Células da endoderme com substâncias fenólicas. $(\mathrm{Ed}=$ endoderme). Barras $=30 \mu \mathrm{m}(13), 75 \mu \mathrm{m}(14-16)$.

Figures 13-16. Root cross-sections. 13. Polarized light showing the Casparian strips (arrows). 14-15. Polarized light showing the suberin lamella in endodermis. 16. Phenolic compounds in endodermis cells. $(\mathrm{Ed}=$ endodermis $)$. Bars $=30 \mu \mathrm{m}(13), 75 \mu \mathrm{m}(14-16)$. 
estrela ou braciformes, pelo processo esquisógeno; a lise inicia-se posteriormente, após completa diferenciação dos elementos vasculares. Para Mani (1962) a inanição e falta de oxigênio são fatores envolvidos na formação dos espaços intercelulares lisígenos que podem ser decorrentes da alta lignificação de células corticais mais internas, fato constatado no presente trabalho. Aquele autor e Seago \& Marsh (1989) admitem que o espessamento da hipoderme também seja um pré-requisito para a formação do aerênquima. Para Drew et al. (1979) o aerênquima das raízes de Zea mays é formado pela ação do etileno que promove o colapso das células; no girassol, Kawase (1979) e Kawase \& Whitmoyer (1980) observaram que o aerênquima também se forma por ação do etileno o qual estimula a atividade da celulase levando as células à plasmólise e em seguida, à morte. De acordo com estes autores, a baixa aeração do solo causada pelo alagamento faz com que o etileno se acumule nos tecidos corticais. Admite-se que a formação do aerênquima nas raízes de $C$. giganteus esteja relacionada com os fatores acima citados, pois, além de apresentar tais caracteres, a espécie é anfíbia.

De acordo com Justin \& Armstrong (1987), a formação de aerênquima lisígeno ou esquisógeno está relacionada com a forma e tipo de diferenciação das células corticais. O tipo de arranjo celular cúbico é mais relacionado com a formação do aerênquima nas espécies que sofrem alagamento, pois neste tipo o contato entre células adjacentes tende a ser menor o que leva mais rapidamente à separação celular. Nas espécies de Cyperaceae, observadas pelos autores, o aerênquima é característico de raízes com células dispostas em fileiras radiais e com forma cúbica, como observado para $C$. giganteus.

A natureza química das estrias de Caspary difere entre as espécies. Van Fleet (1942) sugeriu uma combinação de "lignina - suberina - ácidos graxos", Wilson \& Peterson (1983) a descrevem como composta por lignina, suberina ou ambos. Estes autores observaram em 27 espécies variações entre a presença de suberina, apenas lignina ou, suberina e lignina. Nas raízes de Ranunculus acris (Scott \& Peterson 1978), as estrias de Caspary são impregnadas com lipídios e possivelmente lignina e a lamela de suberina cora-se positivamente para lipídios e fenóis. Em Cyperus giganteus, as estrias de Caspary, assim como a lamela de suberina, coram-se fortemente pelo Sudan IV indicando substâncias lipofílicas. A presença de substâncias fenólicas na endoderme foi também observada em raiz de Ranunculos acris por Scott \&
Peterson (1978). Para Van Fleet (1942) a incompleta oxidação das gorduras e óleos aromáticos na endoderme é responsável pela deposição da lignina, suberina e taninos. De acordo com Howe \& Westley (1988) as substâncias fenólicas desempenham função de proteção contra microorganismos do solo, sendo que em C. giganteus, essas substâncias estão presentes também nas células corticais mais internas, o que deve intensificar esta barreira.

As raízes adventícias de Cyperus giganteus originam-se a partir do meristema de espessamento primário (MEP) ou a partir do meristema de espessamento secundário (MES) do rizoma, como referido para essa espécie por Rodrigues \& Estelita (2002) e para outras monocotiledôneas (Rudall 1991) como Allium cepa (DeMason 1979, 1893). Também Gifford \& Bayer (1995) ao analisarem a origem das raízes de Cyperus esculentus admitem que as mesmas são originadas do MEP, denominado por eles de camada endodermóide. No presente estudo, observa-se ainda, que o primórdio radicular apresenta-se truncado devido, provavelmente, à compressão cortical.

Conclui-se que as raízes de Cyperus giganteus apresentam caracteres anatômicos constantes para a família Cyperaceae e condizentes com o seu hábito (grande tempo submeras).

Agradecimentos - As autoras agradecem à Fapesp (processos 97/05516-0 e 00/01040-6) por auxílios recebidos.

\section{Referências bibliográficas}

ALLEM, A.C. \& VALLS, J.F.M. 1987. Recursos forrageiros nativos do Pantanal Matogrossense. Empresa Brasileira de Pesquisa Agropecuária, Centro Nacional de Recursos Genéticos. Brasília.

ALQUINI, Y. \& MORRETES, B.L. 1996. Organização estrutural da raiz de Musa rosaceae Jacq. (Musaceae). Arquivos de Biologia e Tecnologia 39:657-669.

BUKATSCH, F. 1972. Bemerkungen zur Doppelfärbung Astrablau-Safranin. Mikrokosmos 6:255.

CLARCK, L.H. \& HARRIS, W.H. 1981. Observations on the root anatomy of rice (Oryza sativa L.). American Journal of Botany 68:154-161.

CLOWES, F.A.L. 1954. The promeristem and the minimal constructional centre in grass root apices. New Phytologist 53:108-116.

CLOWES, F.A.L. 1981. The difference between open and closed meristems. The New Phytologist 57:85-88.

CLOWES, F.A.L. 1994. Origin of the epidermis in root meristems. The New Phytologist 127:335-347.

CLOWES, F.A.L. 2000. Pattern in root meristem development in angiosperms. The New Phytologist 146:83-94. 
DAVIES, J., BRIARTY, L.G. \& RIELEY, J.O. 1973. Observations on the swollen lateral roots of the Cyperaceae. New Phytologist 72:167-174.

DEMASON, D.A. 1979. Histochemistry of the primary thickening meristem in the vegetative stem of Allium cepa L. American Jounal of Botany 66:347-350.

DEMASON, D.A. 1983. The primary thickening meristem: definition and function in monocotyledons. American Journal of Botany 70:955-962.

DREW, M.C., JACKSON, M.B. \& GIFFARD, S. 1979. Ethylenepromoted adventitiouns rooting and development of cortical air spaces (aerenchyma) in roots may be adaptive responses to flooding in Zea mays L. Planta 147:83-88.

ESAU, K. 1940. Developmental anatomy of the fleshy storage organ of the Daucus carota. Hilgardia 13:175-226.

ESAU, K. 1943. Origin and development of primary vascular tissues in seed plants. The Botanical Review 4:125-206.

ESAU, K. 1967. Plant anatomy. John Wiley \& Sons, New York.

ESTELITA, M.E.M. 1993. Anatomia dos órgãos vegetativos de Remirea maritima Aubl. (Cyperaceae). Naturalia 18:123-134.

GIFFORD, E.M. \& BAYER, D.E. 1995. Development anatomy of Cyperus esculentus (yellow nutsedge). International Journal of Plant Sciences 156:622-629.

GOVINDARAJALU, E. 1974. The systematic anatomy of South Indian Cyperaceae: Cyperus L. subgn. Juncellus, Cyperus subg. Mariscus and Lipocarpha R. Br. Botanical Journal of Linnean Society 68:235-266.

HEIMSCH, C. 1951. Development of vascular tissues in barley roots. American Journal of Botany 38:523-537

HOWE, H.F. \& WESTLEY, L.C. 1988. Ecological relationships of plants and animals. Oxford Universty Press, New York.

JOHANSEN, D.A. 1940. Plant microtechnique. McGraw-Hill, New York.

JUSTIN, S.H.F.W. \& ARMSTRONG, W. 1987. The anatomical characteristics of roots and plant response to soil flooding. New Phytologist 106:465-495.

KADEJ, F. 1963. Interpretation of the pattern of the cell arrangement in the root apical meristem of Cyperus gracilis L. var. alternifolius. Acta Soccietatis Botanicorum Poloniae 32:295-301.

KAWASE, M. 1979. Role of cellulase in aerenchyma development in sunflower. American Journal of Botany 66:183-190.

KAWASE, M. \& WHITMOYER, R.E. 1980. Aerenchyma development in waterlogged plants. American Journal of Botany 67:18-22.

KUKKONEN, I. 1967. Vegetative anatomy of Uncinia (Cyperaceae). Annals of Botany 31:523-544.

MANI, P.A. 1962. Air-space tissue in Cyperus. Science and Culture 28:39-40.

METCALFE, C.R. 1971. Anatomy of the monocotyledons. Cyperaceae v.5. University Press, London.
PITA, P.B. \& MENEZES, N.L. 2002. Anatomia da raiz de espécies de Dyckia Schult. f. e Encholirium Mart. ex Schult. \& Schult. f. (Bromeliaceae, Pitcairnioideae) da Serra do Cipó (Minas Gerais, Brasil), com especial referência ao velame. Revista Brasileira de Botânica 25:25-34.

RIOPEL, J.L. \& STEEVES, T.A. 1964. Studies on the roots of Musa acuminata cv. Gros Michel. I. The anatomy and development of main roots. Annals of Botany 28:475-490.

RODRIGUES, A.C. \& ESTELITA, M.E.M. 2002. Primary and secondary development of Cyperus giganteus Vahl rhizome (Cyperaceae). Revista Brasileira de Botânica 25:251-258.

RUDALL, P. 1991. Lateral meristems and stem thickening growth in monocotiledons. The Botanical Review 57:150-163.

ROST L.T. 1994. Root tip organization and the spatial relationships of differentiation events. In Vascular Plants (M. Iqbal, ed.). Timber Press, Portland, p.59-89.

SASS, J.E. 1951. Botanical Microtechnique. The Iowa State College Press, Iowa.

SCATENA, V.L. \& MENEZES, N.L. 1996. Anatomia de raízes de Syngonanthus Ruhl. (Eriocaulaceae). Revista Brasileira de Biologia 56:333-343.

SCOTT, M.G. \& PETERSON, R.L. 1978. The root endodermis in Ranunculus acris. II Histochemistry of the endodermis and the systhesis of phenolic compounds in roots. Canadian Journal of Botany 57:1063-1077.

SCULTORPE, C.D. 1967. The biology of aquatic vascular plants. Edward Arnold, London.

SEAGO, J.L. \& MARSH, L.C. 1989. Adventitious root development in Typha glauca, with emphasis on the cortex. American Journal of Botany 76:909-923.

SEAGO, J.L., PETERSON, C.A. \& ENSTONE, D.E. 1999. Cortical ontogeny in roots of the aquatic plant, Hydrocharis morus-ranae L. Canadian Journal of Botany 77:113-121.

SEAGO, J.L., PETERSON, C.A. \& ENSTONE, D.E. 2000. Cortical development in roots of the aquatic plant Pontederia cordata (Pontederiaceae). American Journal of Botany 87:1116-1127.

SEUBERT, E. 1997. Root anatomy of palms. Flora 192:81-103.

SHARMA, O.P. \& MEHRA P.N. 1972. Systematic anatomy of Fimbristylis Vahl (Cyperaceae). Botanical Gazette 133:87-95.

TOMLINSON, P.B. 1969. On the morphology and anatomy of turtle grass, Thalassia testudinum (Hydrocharitaceae). II. Anatomy and development of the root in relation to function. Bulletin of Marine Science 19:57-71.

TORREY, J.G. \& FELDMAN L.J. 1977. The organization and function of root apex. American Scientist 65:334-344.

VAN FLEET, D.S. 1942. Development and distribution of the endodermis and an associated oxidase system in monocotyledonous plant. American Journal of Botany 29:1-15. 
VAN FLEET, D.S. 1961. Histochemistry and function of the endodermis. Botanical Review 27:165-220.

VIANNA, W.O., SOARES, M.K.M. \& APPEZZATO-DAGLÓRIA, B. 2001. Anatomia da raiz escora de Philodendron bipinnatifidum Schott (Araceae). Acta Botanica Brasílica 15:313-320.

WILDER, G.J. 1986a. Anatomy of first-order roots in the Cyclanthaceae (Monocotyledoneae). I. Epidermis, cortx and pericycle. Canadian Journal of Botany 64:2622-2644.

WILDER, G.J. 1986b. Anatomy of first-order roots in the Cyclanthaceae (Monocotyledoneae). II. Stele (excluding pericycle). Canadian Journal of Botany 64:2848-2864.
WILLIAMS, B.C. 1947. The structure of the meristematic root tip and origin of the primary tissues in the roots of vascular plants. American Journal of Botany 34:455-462.

WILSON, C.A. \& PETERSON, C.A. 1983. Chemical composition of the epidermal, hypodermal, endodermal and interveing cortical cell walls of various plants roots. Annals of Botany 51:759-769.

WILLS, G.D., HOAGLAND, R.E. \& PAUL, R.N. 1980. Anatomy of yellow nutsedge (Cyperus esculentus). Weed Science 28:432-437.

ZUCKER, W.V. 1983. Tannins: does structure determine function? An ecological perspective. The American Naturalist 121:335-365. 